Int. J. Morphol.,

33(3):948-954, 2015.

\title{
The Carpal Joint of the Donkey (Equus asinus): Morphological Investigation
}

\author{
Articulación del Carpo del Asno (Equus asinus): Investigación Morfológica
}

\author{
Mohamed A. M. Alsafy"; Samir A.A. El-Gendy* \& Howaida M. Abou-Ahmed**
}

\begin{abstract}
ALSAFY, M. A. M.; EL-GENDY, S. A. A. \& ABOU-AHMED, H. M. The carpal joint of the donkey (Equus asinus): Morphological investigation. Int. J. Morphol., 33(3):948-954, 2015.

SUMMARY: The current study has been achieved to be an essential resource for all veterinary practitioners that deal with the anatomy of the carpal joint of the donkey. Ten adult donkeys of both sexes were used in the current study. The topographical approach to the carpal joint was investigated in this study. Radiography and computed tomography (CT) of the carpus delineated the articulations of the carpal joint: radiocarpal, intercarpal, and carpometacarpal. The carpal ligaments were well delineated and the carpal canal was demonstrated with its content such as superficial digital flexor tendon (SDFT) and deep digital flexor tendon (DDFT). The contrast radiography visualized that the radiocarpal joint outpouched proximal to the accessory carpal bone by large palmarolateral pouch and small palmaromedial pouch, however the intercarpal joint outpouched distal to the accessory carpal bone by two small palmarolateral and palmaromedial pouches. The carpometacarpal joint showed medial and lateral palmarodistal outpouchings in distal direction between the corresponding 2nd and 4th metacarpal bones and the 3rd metacarpal bone. Scanning electron microscopy (SEM) displayed two types of synoviocytes macrophages type A cells and fibroblast like type B cells at the cellular lining of the synovial membrane of the joint capsule.
\end{abstract}

KEY WORDS: Carpal joint; Donkey; Radiography; Computed tomography; Scanning electron microscopy.

\section{INTRODUCTION}

The donkey is an important farming animal used heavily by the Egyptian farmers because of their great tolerance as a draught animal. The carpal joint consists of the three chief joints; the antebrachiocarpal joint, intercarpal and carpometacarpal joints between all carpal bones (Budras et al., 2012; Getty, 1975; König et al., 2007).

Radiography is the most used imaging tool for the diagnosis of the bony disorders of the limbs of equine (Semieka \& Ali, 2012; Vanderperren \& Saunders, 2009). Radiography remains the main stay of equine musculoskeletal imaging due to its low cost, ready accessibility and global evaluation of bony structures (Butler et al., 2011; Kinns \& Nelson, 2010).

The computed tomography (CT) was efficient imaging modality that provides a cross-sectional image with superior soft tissue differentiation and no superimposition of the overlying structures, which can be used for better diagnosis of foot abnormalities (Badawy, 2011). The computed tomography through its high spatial resolution and moderate differentiation of tissue contrast is a fastened exceptionally useful technique for visualizing general anatomy (Dixon \&
Dacre, 2005). CT is particularly useful for diagnosis of injuries affecting the carpal bones (sclerosis, fracture), the wall and contents of the carpal sheath (deep digital flexor tendon, superficial digital flexor tendon, accessory ligament of the superficial digital flexor tendon, flexor retinaculum, palmar carpal ligament), and the proximal attachment of the suspensory ligament (Bergman \& Saunders, 2011). Accurate interpretation of $\mathrm{CT}$ of the foot requires a thorough knowledge of the cross sectional anatomy of the region and accurate interpretation of the plan metric CT is necessary for the study and evaluation of the pathological condition or damaged tissues, CT is particularly useful for looking at complex bony structures such as the skull, spine or joints (Raji et al., 2008).

Scanning electron microscopy (SEM) is the most useful to visualize the structures and the whole cell shapes of the synovial membrane of the carpal joint capsule and it reports three dimensional structure of the synoviocytes of the carpal joint of equine. The characteristic shape of the cells records their active function such as secretions toward the joint cavity and sensation for signals from the joint cavity (Shikichi et al., 1999). Therefore, the aim of the current study was to introdu-

\footnotetext{
* Anatomy \& Embryology, Faculty of Veterinary Medicine, Alexandria University, Edfina, Egypt.

** Surgery Department, Faculty of Veterinary Medicine, Alexandria University, Edfina, Egypt.
} 
ce an essential resource for students, anatomists, clinicians, surgeons and all veterinary practitioners that dealt with the anatomy of the carpal joint of the donkey.

\section{MATERIAL AND METHOD}

Ten adult donkeys of both sexes free from any joints affection were used in our study. The local animal ethics review panel approved this protocol. The animals were deeply anaesthetized with both pentobarbital and thiopental sodium and were sacrificed by bleeding from common carotid artery.

Anatomical dissection of the carpal joint. Two donkey's carpi were used for studying the gross anatomy of the carpal joint articular surface, joint capsule and ligaments. The joint cavity of one carpal joint were injected with gum milk latex mixed with red colored paints then preserved in freezer for one week and subsequently dissected for studying the joint capsule. Another donkey was being bled after being anesthetized then underwent routine preservative technique ( $10 \%$ formalin mixed with $4 \%$ glycerin and $1 \%$ phenol for 14 days until complete fixation and then its carpus were separated and routine dissection was performed (Fig. 1).

Radiology. Four donkeys were used. Two donkey's carpi radiographied without contrast media and two donkey's carpi were injected with a mixture of $75 \mathrm{~g}$ red lead oxide in $150 \mathrm{cc}$ gum milk latex at the radiocarpal joint and with an eventually mixture of $75 \mathrm{~g}$ red lead oxide in $150 \mathrm{cc}$ gum milk latex colored blue with metheyline blue stain at the intercarpal joint, where two depressions were observed medial to the extensor carpi radialis tendon and common digital extensor tendon on the dorsal surface of the carpal joint after being flexed, the needle inserted perpendicular in the depressions. The four carpi freshly isolated from limbs, were transported to the $\mathrm{x}$-ray center within two hours, and imaged using Toshiba $500 \mathrm{ml}$ apparatus for $\mathrm{x}$-rays in dorsopalmar view and mediolateral view. After that, they were preserved in a freezer for 3 to 4 days then dissected (Fig. 2).

Computed tomography. Two donkey's carpi were used for studying CT of the joints. The joints were severed and transferred to the CT center within two hours. Sagittal, dorsal, and transverse images were obtained using a Toshiba asteion super 4 multi slice $4 \mathrm{CT}$ apparatus. The distance between the slices taken was $0.5 \mathrm{~cm}$.

Scanning electron microscopy. Two donkey's carpi were used for SEM. Tissues samples were dissected from the synovial membrane of the carpal joint capsule from right and left limbs (Shikichi et al.). The samples were fixed in a mixture of paraformaldehyde $2.5 \%$ and glutaraldehyde $2.5 \%$ solution in $0.1 \mathrm{M}$ phosphate buffer for four hours at $4{ }^{\circ} \mathrm{C}$. After washing in the equivalent buffer, the specimens were post-fixed in osmium tetroxide $1 \%$ in a phosphate buffer for two hours, followed by washing in the same buffer. The samples were subsequently dehydrated in ascending grades of ethanol followed by critical point drying in carbon dioxide, after that sputter-coated with gold and examined with JEOL JSM 5300 scanning electron microscope operating at $20 \mathrm{Kv}$, at the Faculty of Science, Alexandria University.

\section{RESULTS}

Anatomical structures of the carpal joint. The carpal joint is composed of three horizontal levels of articulations; the antebrachiocarpal or radiocarpal joint is proximal joint located between the distal articular surface of radius and the proximal row of carpal bones. The intercarpal or mediocarpal is the middle joint located between the proximal and distal row of carpal bones. The carpometacarpal joint is the distal joint located between the distal row of carpal bones and the proximal articular surface of the third metacarpal bone. Articulations also exist between the adjacent carpal bones of each row.

The carpal joint capsule is comprised of a common outer fibrous capsule and three inner synovial pouches, one for each joint. The fibrous capsule attached proximally to the distal extremity of the radius just proximal to its articular surface. Distally it is attached around the articular surface of the base of the third metacarpal bone. There was no communication between the radiocarpal and intercarpal joint while the intercarpal joint communicated with carpometacarpal joint between the third and fourth carpal bones. The radiocarpal synovial sac outpouched palmary, proximal to the accessory carpal bone by large palmarolateral pouch (Fig. 3, number 4) and small palmaromedial pouch (Fig. 3, number 5). The intercarpal synovial sac was associated to the adjoining articular surfaces of the two carpal rows. It sent proximal and distal extensions that pass into the intervals between the individual bones of the two rows as far as the interosseus ligaments, the intercarpal synovial sac outpouched palmary distal to the accessory carpal bone by palmarolateral pouch (Fig. 3, number 6) and palmaromedial pouch (Fig. 3, number 7) whatever the carpometacarpal joint extended laterally and medially by palmarodistal outpouchings in distal direction between the corresponding $2^{\text {nd }}$ and $4^{\text {th }}$ metacarpal bones and the third metacarpal bone. The fibrous joint capsule is strengthened by the extensor retinaculum on the dorsal aspect and the flexor retinaculum on the palmar aspect. 


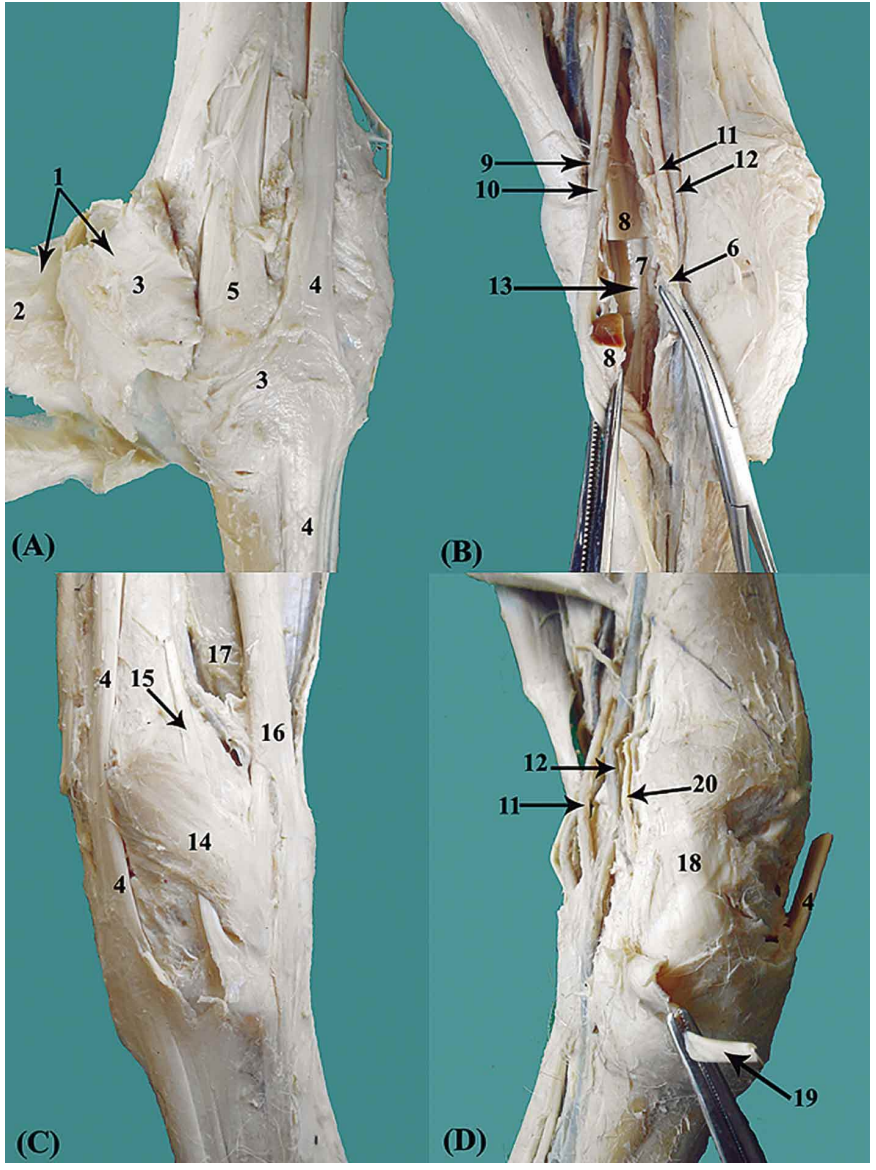

Fig. 1. Anatomical dissection of the carpus; (A) Dorsal view, (B) Palmar view, (C) Lateral view and (D) Medial view. 1. Extensor retinaculum, reflected: 2 . superficial fascia, 3. Deep fascia. 4. Common digital extensor tendon. 5. Extensor carpi radialis tendon. 6. Transverse palmar carpal ligament, reflected. 7. Palmar carpal ligament. 8. Superficial and deep flexor tendon, reflected. 9. Medial palmar nerve. 10. Medial palmar artery. 11. Radial artery. 12. Radial vein. 13. Carpal canal. 14. Lateral collateral ligament. 15. Lateral digital extensor tendon. 16. Ulnaris lateralis tendon. 17. Superficial and deep flexor tendon sheath. 18. Medial collateral ligament. 19. Extensor carpi obliquus tendon. 20. Radial nerve.

The carpal canal enclosed both the superficial and deep digital flexor tendon (Fig. 1B, number 8) within a common synovial sheath and the medial palmar artery and nerve (Fig. 1B, number 9-10).

The carpal ligaments were classified into short ligaments that attached the carpal bones of the same row together and the bones of the distal row with the metacarpus and long medial (Fig. 1D, number 18) and lateral collateral ligaments (Fig. 1C, number 14). The medial collateral ligament extended between the medial styloid process of the radius and the proximal extremity of the $2^{\text {nd }}$ metacarpal bone by long superficial branch and to the second carpal bone by short deep branch. The lateral collateral ligament originated from an eminence on the lateral styloid process of the radius and two parts a long superficial branch that inserted at an eminence on the lateral aspect of the proximal extremity of the fourth metacarpal bone and two deep short branches that inserted at the ulnar carpal bone and fourth carpal bone. The dorsal carpal ligament formed by the fibrous layer of the joint capsule and represented extensor retinaculum surrounded the extensor tendon on the dorsal aspect of the carpus which blends on each side with the collateral ligaments (Fig. 1A, number 1). The palmar carpal ligament formed by thickening of the fibrous layer of the joint capsule and is composed of obliquely crossing fibers arranged in layers. These layers provide a smooth surface over the irregularities of the palmar surface of the carpus and form the dorsal wall of the carpal canal (Fig. 1B, number 7). It originated proximally just above the carpal articular surface of the radius and inserted to the palmar aspect of the metacarpus. The transverse palmar carpal ligament attached from the mediopalmar aspect of the joint to the palmar edge of the accessory bone on the palmar aspect of the joint that completely closed the carpal canal (Fig. 1B, number 6).

Radiographic images of the carpal joint. The dorsopalmar and mediolateral radiographic views showed the carpal bones and the articulations of the carpal joint; antebrachiocarpal, mediocarpal and carpometacarpal or the articulations between the carpal bones of each row (Fig. 2A-C). In the dorsopalmar radiographs; a radiolucent canal was detected between the radial and intermediate carpal bones (Fig. 2A, number 10). A large approximately circular translucent zone in the center of the distal extremity of the radius was seen, it was the depression between the medial and lateral styloid processes in the caudal surface of the bone (Fig. 2A, number 3). Two radiolucent focus were observed on the dorsal aspect of the antebrachiocarpal joint that represented the fat in the joint capsule palmar to the extensor carpi radialis tendon sheath (Fig. 2A, number 11). In the mediolateral radiographs; the distal extremity of radius showed a prominent transverse ridge caudally (Fig.2A-B, number 2). Medially and laterally the medial and lateral collateral ligaments of the carpus attached to medial and lateral styloid processes (Fig. 2A, number 4 and 5). Distal to the radial transverse ridge depressions for attachment of carpal ligaments were noticed (Fig. 2A, number 3). The radial carpal bone was prominent, slightly dorsolateralpalmaromedial obliquity (Fig.2A-C/6). The intermediate carpal bone projected most dorsally in the proximal row and it had a relatively straight dorsal border (Fig. 2A-C, number 7). The accessory carpal bone was seen relatively thin, however thick at its palmar aspect due to tendon and ligament insertions (Fig. 2B-C, number 9). All the distal 


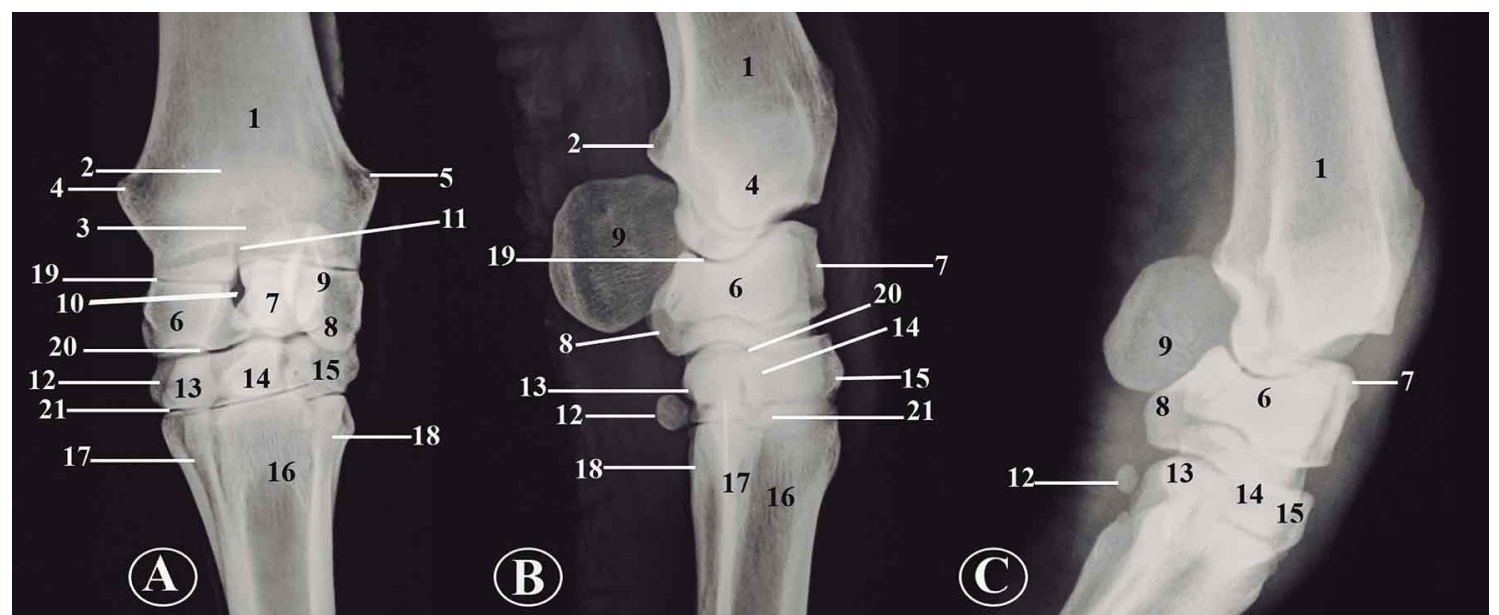

Fig. 2. Radiography of the carpal joint; (A) Dorsopalmar radiograph, (B and C) mediolateral radiographs. 1. The distal extremity of the radius. 2. Transverse ridge on the radius. 3. Translucent depression on the caudal surface of the radius. 4. Medial styloid process of the radius. 5. Lateral styloid process of the ulna. 6. Radial carpal bone. 7. Intermediate carpal bone. 8. Ulnar carpal bone. 9. Accessory carpal bone. 10. Radiolucent canal between the radial and intermediate carpal bone. 11. Fat above antebrachiocarpal joint. 12. First carpal bone. 13. Second carpal bone. 14. Third carpal bone.

row of carpal bones was clearly detected (Fig. 2A-C). The first carpal bone showed variations in two different animal's radiographs by mediolateral radiographs, the first carpal bone noticed articulate with the second carpal bone (Fig. 2B, number 12) and separated from the second carpal bone (Fig. $2 \mathrm{C}$, number 12). In contrast dorsopalmar and mediolateral radiographic views and dissected casted carpus, the synovial layer of carpal joint capsule showed three sacs corresponding to the three main articulations of the carpal joint. The radiocarpal sac was the most proximal and capacious one, enclosed the articular surfaces entering in the formation of joint, as well as that part of the joint between the individual bones of the proximal carpal row, above their interosseus ligaments and the joint between the accessory and ulnar carpal bones. The radiocarpal synovial sac outpouched palmary proximal to the accessory carpal bone by large palmarolateral pouch (Fig. 3, number 4) and small palmaromedial pouch (Fig. 3 , number 5). The intercarpal synovial sac was associated to

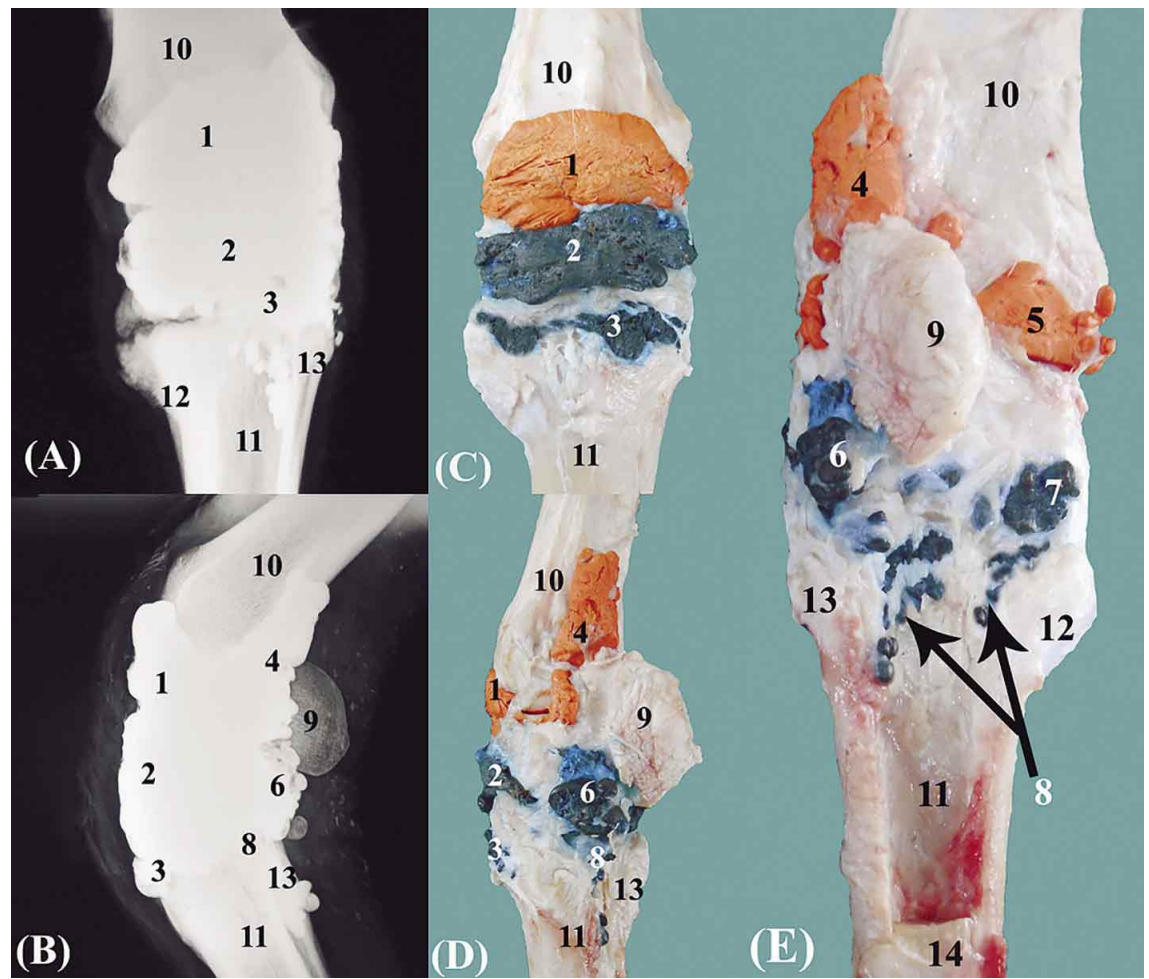

Fig. 3. Contrast radiographic and dissected cast images of the carpal joint: (A) dorsopalmar contrast radiograph. (B) Mediolateral contrast radiograph. (C) Dorsal view of dissected carpus with cast. (B) Lateral view of dissected carpus with cast. (E) Palmar view of dissected carpus with cast. 1. Radiocarpal joint. 2. Intercarpal joint. 3. Carpometacarpal joint. 4. Palmarolateral pouch of radiocarpal sac. 5.Palmaromedial pouch of radiocarpal sac. 6. Palmarolateral pouch of intercarpal sac. 7 . Palmaromedial pouch of intercarpal sac. 8. Palmarodistal pouch of carpometacarpal sac. 9. Accessory carpal bone. 10. Radius. 11. 3rd metacarpal. 12. 2nd metacarpal bone. 13. 4th metacarpal bone. 14 . Suspensory ligament. 
the adjoining articular surfaces of the two carpal rows. It sent proximal and distal extensions that pass into the intervals between the individual bones of the two rows as far as the interosseus ligaments, the intercarpal synovial sac outpouched palmary distal to the accessory carpal bone by palmarolateral pouch (Fig. 3, number 6) and palmaromedial pouch (Fig. 3, number 7). The carpometacarpal synovial sac was the least extensive and enclosed the distal articular surface of the distal row and the base of the large metacarpal bone; it extended laterally and medially by palmarodistal outpouchings in distal direction between the corresponding $2 \mathrm{nd}$ and 4 th metacarpal bones and the third metacarpal bone (Fig. 3, number 8). There was not any communication between the radiocarpal and intercarpal synovial sacs while the intercarpal synovial sac communicated with carpometacarpal synovial between the third and fourth carpal bones where the radiocarpal sac appeared with red cast while the intercarpal and carpometacarpal sacs appeared blue cast (Fig. 3, numbers 1,2 and 3).

Computed tomographic scans of the carpal joint. In CT images; the carpal joint was clearly identified (Fig. 4, letters A-F). The radius, carpal and metacarpal bones were clearly appeared (Fig. 4, numbers 1-12). The carpal canal appeared with its content such as the superficial and deep digital flexor tendon. The tendon of common digital extensor muscle appeared on the dorsal surface of the joint circular in shape (Fig. 4, number 20). The carpal canal with its superficial contents and deep digital flexor tendons appeared in transverse Ct images (Fig. 4, number 22). The deep digital flexor tendon (DDFT) was hyperdense (Fig. 4, number 13) as the extensor tendon, but the superficial digital flexor tendon (SDFT) was hypodense (Fig. 4, number 14). The palmar carpal ligament delineated. The antebrachiocarpal, intercarpal and carpometacarpal articulations were visualized (Fig. 4, numbers 24-26).

Scanning electron microscopy of the carpal joint. The synovial membrane largely covered by densely arranged synovial villi (Fig. 5, letter A). The villi appeared varied in shape and length; the longer villi were branched in their tips. The joint capsule showed one to three deep cellular lining in the luminal surface of the synovial membrane, the synovial intima. The synovial intima cells known as synoviocytes, are responsible for the production of synovial fluid and blood and synovial fluid exchange. Two types of synoviocytes were observed type A-synoviocytes and type B-synoviocytes (Fig. 5, letters B-C). Type A-synoviocytes macrophagic like were spherical in shape and densely covered by many microvilli, these synoviocytes distributed densely over the upper region of the synovial villi than the middle or basal regions of villi (Fig. 5A-B, letter A).

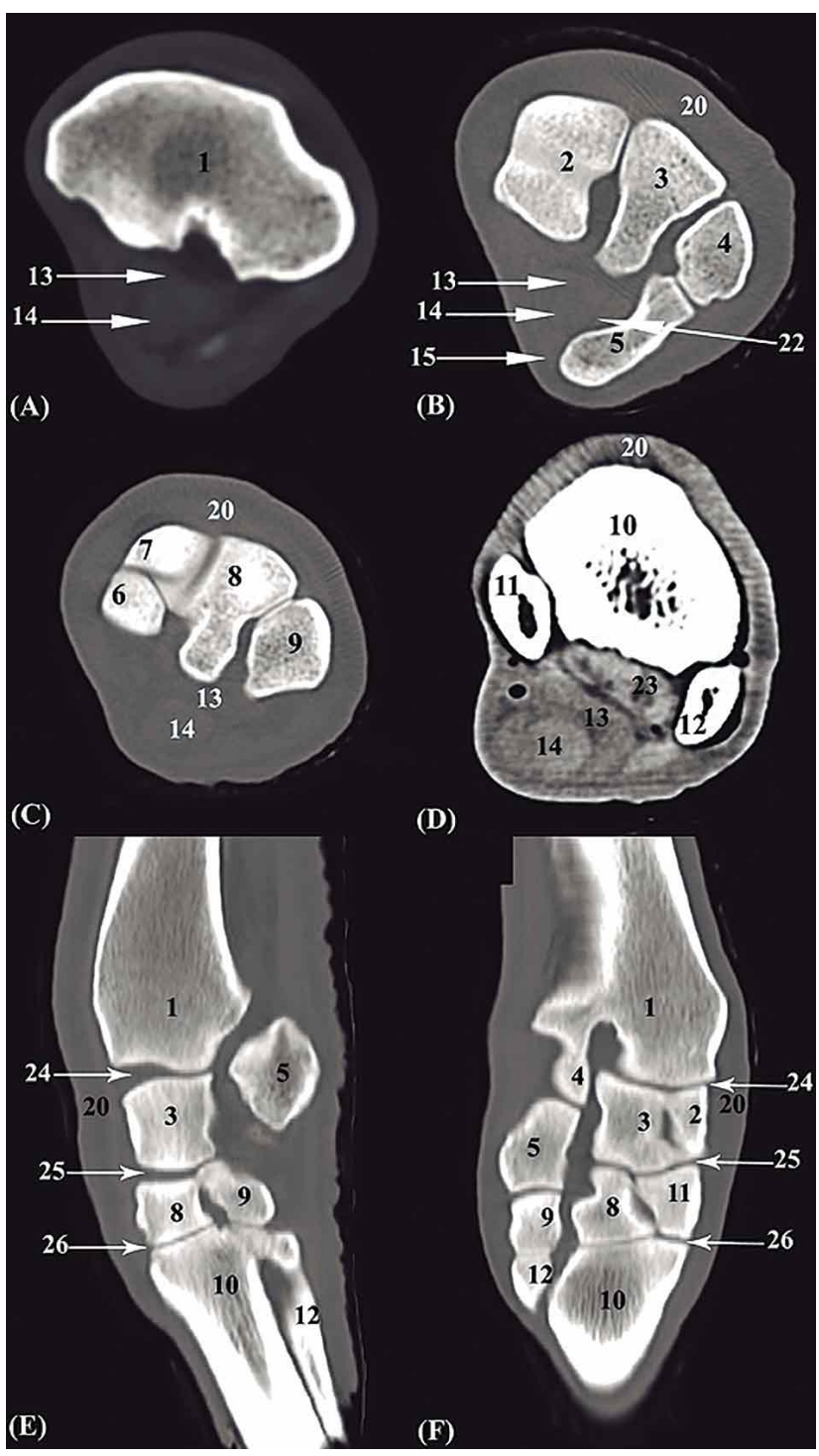

Fig. 4. Transverse CT scans (A, B, C and D) and Sagittal CT scans (E and F) of the carpal joint. A-B. Transverse CT scans at the level of antebrachiocarpal joint. C. Transverse CT scans at the level of intercarpal joint. D. Transverse CT scans at the level of carpometacarpal joint. 1. Distal extremity of the radius. 2. Radial carpal bone. 3. Intermediate carpal bone. 4. Ulnar carpal bone. 5 . Accessory carpal bone. 6. First carpal bone. 7. Second carpal bone. 8. Third carpal bone. 9. Fourth carpal bone. 10. Third metacarpal bone. 11. Second metacarpal bone. 12. Fourth metacarpal bone. 13. Deep digital flexor tendon. 14. Superficial digital flexor tendon. 15. Palmar carpal ligament. 16. Transverse carpal ligament. 20. Common digital extensor tendon. 21. Dorsal carpal ligament. 22. Carpal canal. 23. Suspensory ligament. 24. Antebrachiocarpal joint. 25. Intercarpal joint. 26. Carpometacarpal joint.

Whatever the type B-synoviocytes fibroblastic cells constantly distributed over the synovial villi (Fig. 5A-B, letter B), it had many processes crossed to form meshwork on the luminal surface (Fig. 5A-B, letter P). 

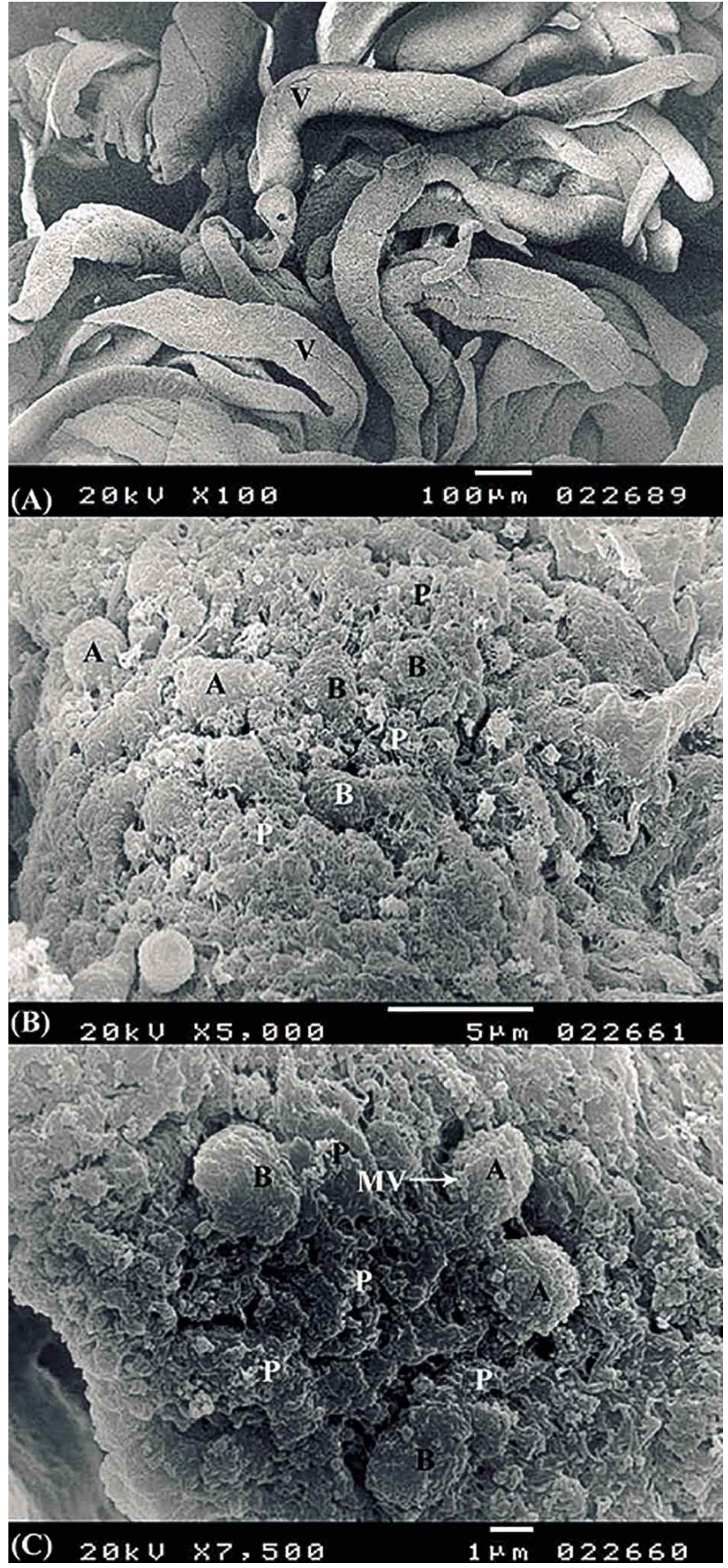

Fig. 5. Scanning electron micrographs (SEM) of the synovial membrane surface of the carpal joint. (A) SEM showed the synovial villi on the luminal synovial surface (X100). (B) SEM showed higher magnification of the luminal surface at the synovial villus tip (X5000). (C) SEM showed higher magnification of the luminal surface at the synovial villus tip (X7500). V. The synovial villi. A. Type Asynoviocytes. B. Type B-synoviocytes. MV. Microvilli on Type Asynoviocytes. P. processes of Type B-synoviocytes formed meshwork along the luminal surface.

\section{DISCUSSION}

The carpus includes the distal end of the radius, the radial, intermediate, ulnar and accessory bones in the proximal row, the first, second, third and fourth bones in the distal row, the proximal end of the metacarpi and the structures adjacent to these osseous components. The wall and contents of the carpal canal (deep digital flexor tendon, superficial digital flexor tendon, accessory ligament of the superficial digital flexor tendon, flexor retinaculum, palmar carpal ligament), the proximal attachment of the suspensory ligament and the carpal joint ligaments were shown in our results were in a line with that mentioned in horse (König et al.).

Through radiography of the carpal joint, the overlaying images confused interpretation and it may be necessary to compare images from several different views to ensure that suspected lesions are not due to overlying images (Butler et al.). Lateromedial radiographs demonstrate the two rows of carpal bones clearly delineated by the radiocarpal, intercarpal and carpometacarpal joints. These joints represented by double lucent lines, as they undulate, rather than forming flat parallel planes (Butler et al.) in horse, the same observed in the current study. In mediolateral radiographs, medially and laterally the medial and lateral collateral ligaments of the carpus appeared (Butler et al.) in horse, this not observed in our study. In contrast radiographic views compared to the same dissected carpus with cast; Our study recorded two palmaromedial and lateral pouches of radiocarpal and intercarpal joints and palmarodistal pouches of carpometacarpal joint in accordance with that recorded in horse by Dyce et al. (2009) and Butler et al.

In CT scans of the carpal joint of the donkey the DDFT was appeared hyperdense while the SDFT appeared hypodense (Kaser-Hotz et al., 1994). The muscles and tendons of the flexor and extensor muscles are located around the carpus and on the dorsal and palmar surfaces of the joints of the feet. A number of these soft tissue structures differentiated in CT. However, due to the lack of fat, delineation is often difficult. Soft tissue structures with small dimensions (tendon sheaths, bursae, fasciae, nerves) hardly can be identified (Schwarz \& Saunders, 2011). The detection of fractures in complex carpal joint is sometimes difficult by radiography because of the superimposition of the different bone structures. In these cases CT can be used for fracture detection or for defining the exact fracture location and configuration (Bergman $\&$ Saunders). 
The ultastuructue morphology of the synovial membrane of the carpal joint the donkey by scanning electron microscopy showed the villi on the synovial membrane that carried out two types of synoviocytes, type A and B. Type A-synoviocytes was spherical and possessed many processes while type B- synoviocytes formed meshwork of processes on the luminal synovial surfaces (Iwanaga et al., 2000; Shikichi et al.; Steinberg \& Hodde, 1990).

ALSAFY, M. A. M.; EL-GENDY, S. A. A. \& ABOU-AHMED, H. M. Articulación del carpo del asno (Equus asinus): investigación morfológica. Int. J. Morphol., 33(3):948-954, 2015.

RESUMEN: Este estudio constituye un recurso esencial para todos los veterinarios que se ocupan de la anatomía de la articulación del carpo del asno. Fueron utilizados diez asnos adultos, de ambos sexos. Se analizó la articulación del carpo desde un enfoque topográfico. Se realizaron estudios por radiografía y tomografía computarizada para identificar las articulaciones del carpo en su conjunto: radiocarpiana, intercarpiana y carpometacarpiana. Los ligamentos del carpo se encontraron bien delineados y en el canal carpiano se identificó su contenido, como el tendón del flexor digital superficial y el tendón del flexor digital profundo. La radiografía de contraste permitió visualizar que la articulación radiocarpiana se articula proximalmente con el hueso accesorio del carpo a través una larga evaginación palmarolateral y una pequeña evaginación palmaromedial; sin embargo, la articulación intercarpiana se relaciona distalmente con el hueso accesorio del carpo por medio de dos pequeñas evaginaciones, palmarolateral y palmaromedial. La articulación carpometacarpiana mostró evaginaciones palmarodistales, medial y lateral, en dirección distal entre los correspondiente $2^{\circ}$ y $4^{\circ}$ huesos metacarpianos y el $3^{\circ}$ hueso metacarpiano. La microscopía electrónica de barrido muestra dos tipos de células: células A, correspondientes a sinoviocitos macrófagos y células B, correspondientes a fibroblastos, en el revestimiento celular de la membrana sinovial de la cápsula articular.

PALABRAS CLAVE: Articulación del carpo; Asno; Radiografía; Tomografía computadorizada; Microscopía electrónica de barrido.

\section{REFERENCES}

Badawy, A. M. Computed Tomographic anatomy of the fore foot in onehumped camel (Camelus dromedrus). Glob. Vet., 6(4):417-23, 2011.

Bergman, H. J. \& Saunders, J. Veterinary Computed Tomography. Chichester, Wiley-Blackwell, 2011. pp.483-501.

Budras, K. D.; Sack, W. O.; Rock, S.; Horowitz, A. \& Berg, R. Anatomy of the Horse. 6th ed. Hannover, Schluetersche, 2012.

Butler, J.; Colles, C.; Dyson, S.; Kold, S. \& Poulos, P. Clinical Radiology of the Horse. Chichester, Wiley -Blackwell, 2011. pp.182-204.

Dixon, P. M. \& Dacre, I. A review of equine dental disorders. Vet. J., 169(2):165-87, 2005.
Dyce, K. M.; Sack, W. O. \& Wensing, C. J. G. The Forelimb of the Horse. In: Dyce, K. M.; Sack, W. O. \& Wensing, C. J. G. (Eds.). Textbook of Veterinary Anatomy. 4th ed. St. Louis, Saunders, 2009. pp. 595-600.

Getty, R. Sisson and Grossman's The Anatomy of the Domestic Animals. 5th ed. Philadelphia, W. B. Saunders Co., 1975.

Iwanaga, T.; Shikichi, M.; Kitamura, H.; Yanase, H. \& Nozawa-Inoue, K. Morphology and functional roles of synoviocytes in the joint. Arch. Histol. Cytol., 63(1):17-31, 2000.

Kaser-Hotz, B.; Sartoretti-Schefer, S. \& Weiss, R. Computed tomography and magnetic resonance imaging of the normal equine carpus. Vet. Radiol. Ultrasound, 35(6):457-61, 1994.

Kinns, J. \& Nelson, N. Imaging tarsal trauma. Equine Vet. Educ., 22(6):2968, 2010.

König, H. E.; Liebich, H. G. \& Bragulla, H. Veterinary Anatomy of Domestic Mammals: Textbook and Colour Atlas. Schattauer, Verlag, 2007.

Raji, A. R.; Sardari, K. \& Mohammadi, H. R. Normal cross-sectional anatomy of the bovine digit: comparison of computed tomography and limb anatomy. Anat. Histol. Embryol., 37(3):188-91, 2008.

Schwarz, T. \& Saunders, J. Veterinary Computed Tomography. Oxford, Wiley, 2011.

Semieka, M. A. \& Ali, M. M. Radiography of Manus and Pes in hard working donkeys. J. Adv. Vet. Res., 2(1):32-7, 2012.

Shikichi, M.; Kitamura, H. P.; Yanase, H.; Konno, A.; Takahashi-Iwanaga, H. \& Iwanaga, T. Three-dimensional ultrastructure of synoviocytes in the horse joint as revealed by the scanning electron microscope. Arch. Histol. Cytol., 62(3):219-29, 1999.

Steinberg, P. J. \& Hodde, K. C. The morphology of synovial lining of various structures in several species as observed with scanning electron microscopy. Scanning Microsc., 4(4):987-1019, 1990.

Vanderperren, K. \& Saunders, J. H. Diagnostic imaging of the equine fetlock region using radiography and ultrasonography. Part 2: the bony disorders. Vet. J., 181(2):123-36, 2009.

\author{
Correspondence to: \\ Dr. Mohamed Alsafy \\ Assistant Professor of Anatomy \& Embryology \\ Faculty of Veterinary Medicine \\ Alexandria University \\ Edfina, Behera \\ EGYPT
}

Post box: 22785

Tel: 020459157256 or 0201149333802

Email: safy73@yahoo.com

Received: 11-02-2015

Accepted: 04-05-2015 